\title{
Prognostic analysis of triple-negative breast cancer patients treated with adjuvant chemotherapy of fluorouracil, epirubicin and cyclophosphamide
}

\author{
WEILING SUN ${ }^{1 *}$, CHUNHONG LI ${ }^{2 *}$, MEIYAN LIU ${ }^{2}$, WEI LIU ${ }^{2}$, CHUNYU YANG $^{2}$ and LI CAI $^{2}$ \\ ${ }^{1}$ The Department of Endoscopy; ${ }^{2}$ The Fourth Department of Medical Oncology, \\ Harbin Medical University Cancer Hospital, Harbin, Heilongjiang 150040, P.R. China
}

Received February 13, 2015; Accepted January 15, 2016

DOI: $10.3892 / \mathrm{ol} .2016 .4176$

\begin{abstract}
The aim of the present study was to investigate the association between the clinicopathological and demographic factors, and the survival time of patients with triple-negative breast cancer (TNBC) in China. The patients had received adjuvant chemotherapy consisting of 5-fluorouracil, epirubicin and cyclophosphamide (FEC; $500 \mathrm{mg} / \mathrm{m}^{2}$ cyclophosphamide, day $1 ; 75 \mathrm{mg} / \mathrm{m}^{2}$ epirubicin, day $1 ; 500 \mathrm{mg} / \mathrm{m}^{2} 5$-fluorouracil, days 1 and 8; every 3 weeks, for at least 4 cycles). The clinicopathological and demographic factors affecting the outcome of the patients with TNBC that received adjuvant FEC chemotherapy were evaluated. Within these variables, the overall survival (OS) and disease-free survival (DFS) times were analyzed using the log-rank test, which was constructed using the multivariate Cox proportional hazards regression model and Kaplan-Meier analysis. Additionally, Spearman's $\chi^{2}$ test was used to analyze categorical variables. In the univariate statistical analysis, the significant risk factors for TNBC patient survival were the stage of disease and lymph node status, which were associated with the OS and DFS, and the total number of pregnancies, which was associated with the DFS. In the multivariate Cox proportional hazard model, lymph node status was an independent prognostic indicator of OS
\end{abstract}

Correspondence to: Dr Li Cai, The Fourth Department of Medical Oncology, Harbin Medical University Cancer Hospital, 150 Haping Road, Harbin, Heilongjiang 150040, P.R. China

E-mail: sunweiling0@163.com

${ }^{*}$ Contributed equally

Abbreviations: TNBC, triple negative breast cancer; FEC, fluorouracil, epirubicin and cyclophosphamide; OS, overall survival; DFS, disease-free survival; AUC, area under curve; ER, estrogen receptor; PgR, progesterone receptor; HER2, human epidermal growth factor receptor 2

Key words: triple negative breast cancer, fluorouracil, epirubicin, cyclophosphamide, overall survival, disease-free survival, lymph node status
$[\mathrm{P}<0.001$; hazard ratio (HR), 1.996; 95\% confidence interval (CI), 1.465-2.720] and DFS $(\mathrm{P}<0.001$; HR, 1.824; 95\% CI, 1.315-2.531). By the Kaplan-Meier method, the stage of disease and lymph node status demonstrated a significant effect on OS and DFS. Patients with the lymph node status N3 and stage III disease possessed a poor prognosis and survival. An association between lymph node status and the tumor recurrence and mortality rate was identified. The area under the curves of the lymph node status for TNBC recurrence and mortality were $0.676(\mathrm{P}=0.002)$ and $0.685(\mathrm{P}=0.001)$, respectively. Additionally, the number of pregnancies was associated with tumor size, lymph node status and stages of disease. Lymph node status is an independent prognostic indicator of OS and DFS to TNBC patients with FEC adjuvant chemotherapy.

\section{Introduction}

Breast cancer is one of the most common malignancies and leading causes of cancer-associated mortalities among females (1). Based on DNA microarray techniques, breast cancer is classified into five subtypes: Luminal A; luminal B; normal breast-like; human epidermal growth factor receptor 2 (HER2/neu) overexpressing; and basal-like (2). The subtype that is immunohistochemically characterized by the lack of expression of the estrogen receptor (ER), progesterone receptor $(\mathrm{PR})$ and HER2 is defined as triple negative breast cancer (TNBC) (3).

TNBC, which accounts for $10-15 \%$ of breast cancers, is considered to exhibit an aggressive clinical behavior and poor prognosis, due to the insensitivity of the cancer to endocrine and targeted therapy (4-12). Therefore, chemotherapy is a significant therapy for such cancers. The treatment options for TNBC include anthracyclines, taxanes, platinum and alkylating agents (13-16). However, there is no standard chemotherapy regimen for TNBC.

Based on National Comprehensive Cancer Network guidelines, the adjuvant 5-fluorouracil, epirubicin and cyclophosphamide (FEC) chemotherapy regimen is the suggested regimen for breast cancer. However, there is no conclusion regarding the clinicopathological and demographical factors of TNBC patients that are suitable for adjuvant FEC chemotherapy. Therefore, the aim of the present retrospective study 
is to analyze the association between the clinicopathological and demographical characteristics and the survival of TNBC patients that receive FEC adjuvant chemotherapy.

\section{Materials and methods}

Patients. In total, 956 patients were diagnosed with TNBC, and $25.0 \%$ (239/956) of these patients had received adjuvant FEC chemotherapy with surgery, modified radical mastectomy or breast-conserving surgery plus a sentinel lymph node examination at the Harbin Medical University (Harbin, Heilongjiang, China) between April 2001 and December 2008. These 239 patients were included in the present study. Primary cancers were evaluated in accordance with the 7 th edition of the American Joint Committee on Cancer (AJCC) tumor-node-metastasis (TNM) staging system. The inclusion criteria included females with histologically confirmed ER, PR and HER2-negative breast cancer, between stages I and IIIA. The criteria for TNBC were $0 \%$ expression for ER, $0 \%$ expression for PR and HER 2 expression of 0 or $1^{+}$only. Patients with an immunohistochemical score for HER-2 neu of $2^{+}$demonstrated no HER 2 gene amplification by fluorescence in situ hybridization. These patients had not undergone neoadjuvant chemotherapy and radiotherapy prior to surgery. The exclusion criteria included stage IV disease and a history of other cancers. Pathology reports were obtained from the medical record room of the Harbin Medical University. Data on the demographical and clinical characteristics, extent of disease, and types of surgery, chemotherapy and radiotherapy were collected from the medical records. The data also included the menopausal status based on the hormone level and age, family history of cancer in first and second-degree relatives, tumor size and lymph node status. The number of pregnancies consisted of full-term pregnancies, non-full-term pregnancies and miscarriages. Clinical data of these patients were used for survival analysis.

Treatment. All patients underwent conservative surgery or a modified radical mastectomy. Chemotherapy consisting of adjuvant FEC was administered to patients $\left(500 \mathrm{mg} / \mathrm{m}^{2}\right.$ cyclophosphamide, day $1 ; 75 \mathrm{mg} / \mathrm{m}^{2}$ epirubicin, day $1 ; 500 \mathrm{mg} / \mathrm{m}^{2}$ 5-fluorouracil, days 1 and 8, every 3 weeks, for at least 4 cycles).

Statistical Analysis. The vital status of the study group was assessed from the medical record room. January 30, 2013 was the follow-up completion date. Univariate and multivariate Cox proportional hazard models were used to assess the effects of variables on patient survival (Table I). The parameters were then tested using the multivariate Cox proportional hazards model, which was performed to identify the independent variables for predicting survival. Hazard ratios (HR) and the 95\% confidence intervals (CIs) were recorded for each factor. Disease-free survival (DFS) time was calculated from the date of surgery resection to the date of the final follow-up or relapse. Overall survival (OS) time was defined as the elapsed time between the date of the surgery and the date of last follow-up or mortality. The cut-off value was selected using the receiver operating characteristic (ROC) curve analysis (Fig. 1). Survival was estimated using the Kaplan-Meier method (Fig. 2). Spearman's $\chi^{2}$ test was used to analyze categorical variables
(Table II). $\mathrm{P}<0.05$ was considered to indicate a statistically significant difference. SPSS 19.0 software for Windows (IBM SPSS, Armonk, NY, USA) was used for statistical analysis.

\section{Results}

The demographic and clinical characteristics and the treatment options of the patients are presented in Table I. The average age of patients was $48.3 \pm 9.4$ years (median, 49.0 years; range, 26.0-76.0 years). The average follow-up time was $80.1 \pm 30.4$ months (range, 9.5-144.1 months). The number of pre-menopausal patients was 130 patients, $54.4 \%$ of the total. Of the patients, $6(2.5 \%)$ suffered bone metastases and 25 patients $(10.5 \%)$ suffered visceral metastases. The lymph node metastatic rate of patients with tumor sizes of $<2 \mathrm{~cm}$ was $27.9 \%$ (24/86); however, for tumor sizes of $>2 \mathrm{~cm}$, the rate was as high as $48.4 \%(74 / 153)$.

The results of univariate analysis are shown in Table I. The univariate analysis showed that the lymph node status $(\mathrm{P}<0.001)$ and stage of disease $(\mathrm{P}<0.001)$ were significantly associated with the OS time. The OS time showed no significant difference for age $(\mathrm{P}=0.673)$, menopausal status $(\mathrm{P}=0.574)$, number of pregnancies $(\mathrm{P}=0.544)$, family history $(\mathrm{P}=0.848)$, tumor histology $(\mathrm{P}=0.717)$, adjuvant radiotherapy $(\mathrm{P}=0.585)$, primary surgery $(\mathrm{P}=0.607)$ or tumor size $(\mathrm{P}=0.493)$. The DFS was significantly associated with the lymph node status $(\mathrm{P}<0.001)$ and stage of disease $(\mathrm{P}=0.003)$, but not with the other factors. In the multivariate statistical analysis, the significant independent prognostic variable affecting survival, including OS and DFS time, was lymph node status rather than the stage of disease, despite the stage of disease being a well-characterized independent prognostic factor (Table I)

The prognostic value of lymph node status on TNBC recurrence and mortality was assessed using ROC analysis. The association of lymph node status and tumor recurrence or mortality was identified. The cut-off points for OS and DFS in the study population were each 0.5 . The area under the curves (AUCs) of the lymph node status for TNBC recurrence and mortality were $0.676(\mathrm{P}=0.002 ; 95 \% \mathrm{CI}, 0.580-0.791)$ and 0.685 ( $\mathrm{P}=0.001 ; 95 \% \mathrm{CI}, 0.565-0.788)$, respectively (Fig 1.).

The OS rates of patients following diagnosis were 97.5, 92.1 and $71.1 \%$ at 12,36 and 60 months, respectively; the DFS rates were 95.0, 88.3 and 69.0\%, respectively (Fig. 2). The Kaplan-Meier survival curves stratified for lymph node status and stage of disease are exhibited in Fig. 2. Patients with $\mathrm{N} 3$ or stage III disease tended to demonstrate a shorter OS and DFS compared with patients with N0-2 (OS, P<0.001; DFS, $\mathrm{P}<0.001)$ or stage I-II disease (OS, $\mathrm{P}=0.001$; DFS, $\mathrm{P}=0.005)$ (Fig. 2.).

The tumor size, lymph node status and stage of disease were all associated with the number of pregnancies. Additionally, the lymph node status and stage of disease were associated with primary surgery, and the lymph node status was associated with adjuvant radiotherapy (Table II).

\section{Discussion}

The results of the present study demonstrated that age (45.6 vs. 54.4\%) and menopausal status (54.4 vs. $45.6 \%$ ) did not significantly affect the incidence of TNBC in China. This is 


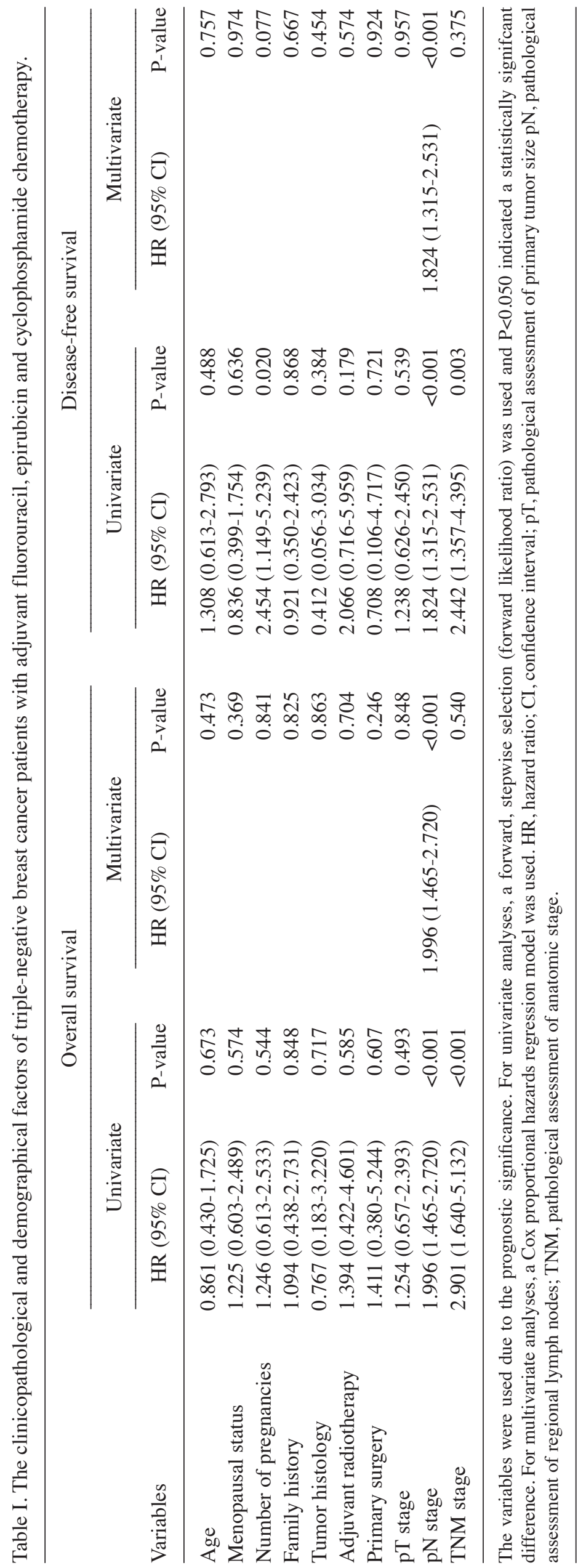




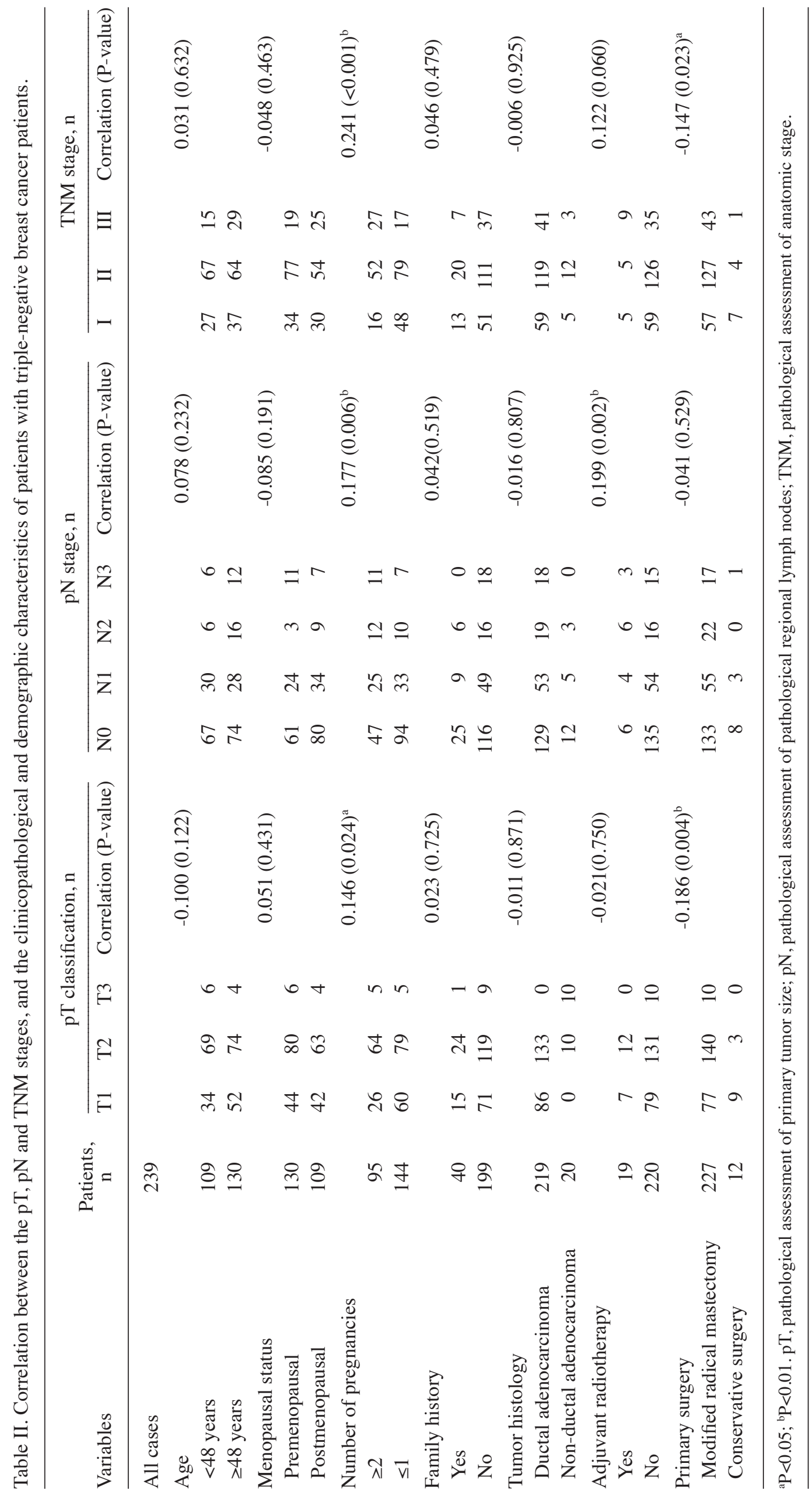



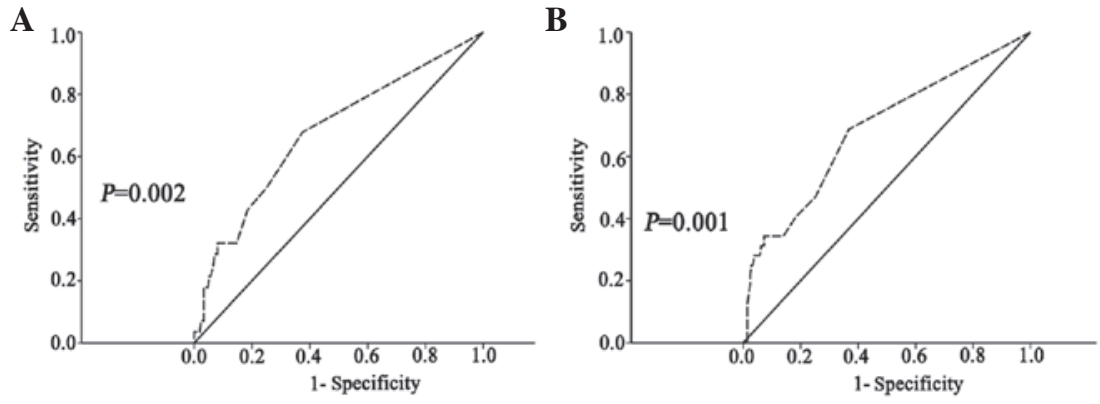

Figure 1. Receiver operating characteristic curves of the effect of lymph node status on TNBC recurrence and mortality. (A) The AUC of lymph node status for TNBC recurrence was 0.676 and $\mathrm{P}=0.002$. (B) The AUC of lymph node status for TNBC-associated mortality was was 0.685 and $\mathrm{P}=0.001$. AUC, area under the curve; TNCB, triple-negative breast cancer.
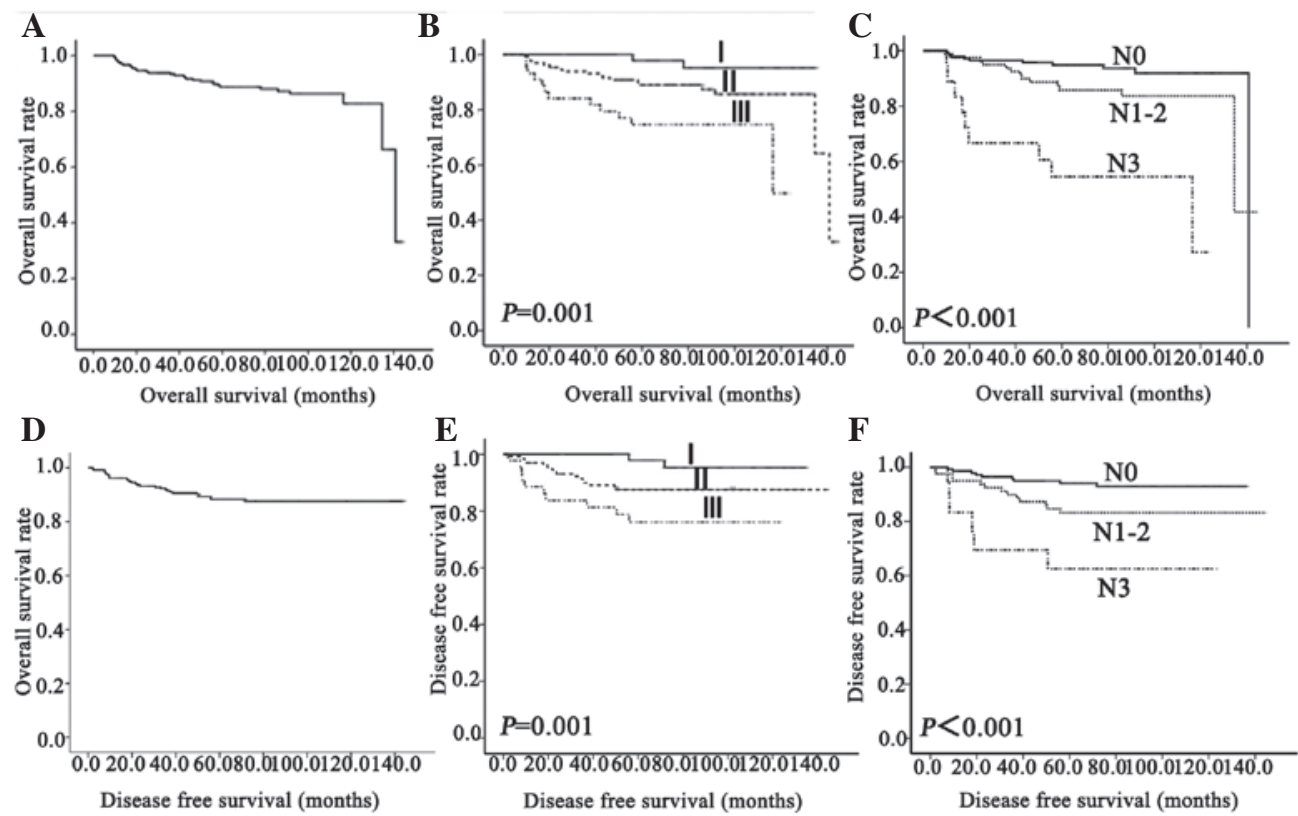

Figure 2. The effect of clinicopathological factors on the OS and DFS rates of triple negative breast cancer patients that underwent adjuvant chemotherapy with fluorouracil, epirubicin and cyclophosphamide. Prognostic significance was assessed using Kaplan-Meier survival estimates and log-rank tests. Graphs compare the OS rates according to (A) all patients, $(\mathrm{B})$ the stage of disease $(\mathrm{P}=0.001)$ and $(\mathrm{C})$ lymph node status $(\mathrm{P}<0.001)$. Graphs compare the DFS rates according to (D) all patients, (E) the stage of disease $(\mathrm{P}=0.005)$ and $(\mathrm{F})$ lymph node status $(\mathrm{P}<0.001)$. OS, overall survival, DFS, disease-free survival.

not in accordance with the findings of previous studies, which report the prevalence of TNBC among non-African female breast cancer patients as between 10 and $17 \%$ and report that TNBC is increased in menopausal females compared with pre-menopausal African females (17-19). Numerous studies have demonstrated that premenopausal African-American females were more prone to develop TNBC $(5,9,17,18)$. Carey et al reported that the morbidity rate of the TNBC subtype among African-American breast cancer patients $<50$ years old is as high as $39 \%$, whereas among Caucasian females and post-menopausal African-American females, the morbidity rate is 16 and $14 \%$ respectively $(5,9,18)$.

TNBC is prone to local recurrence and distant metastasis. In the present study, 6 patients $(2.5 \%)$ suffered bone metastases and 25 patients $(10.5 \%)$ suffered visceral metastases. TNBC has an increased risk of local recurrence or distant metastasis following the final diagnosis $(5,17,18,20-22)$. In the present study, the general disease progression rate is $12.1 \%$ (29/239, the local recurrence rate is $6.7 \%(16 / 239)$ and the distant metastasis rate is $8.8 \%(21 / 239)$. These findings suggest that distant metastasis may exhibit a certain organ tendency in TNBC (23-25) and that the specific target organ metastasis may be associated with specific gene expression (26-28). Dent et al observed that the frequency of distant metastasis was significantly increased among patients with TNBC compared with non-TNBC patients (33.9 and $22.4 \%$, respectively), and the risk of distant metastasis was found to be increased in the TNBC group (relative risk $=2.6$ ) (18). There was a gradual increase in the risk of distant metastasis in the TNBC group, with a peak in the 2nd and 3rd years (18), followed by a rapid decline, with a lower risk in the 5th year and no distant metastasis in the 8th year of follow up (29). Previous studies also reported that TNBC was associated with an increased risk of visceral metastasis and a decreased risk of bone metastasis $(30,31)$. These results are similar to those indicated in the present study.

The variation in the tumor size was not of notable importance in patients with TNBC that possessed no distant metastasis, and had received adjuvant FEC chemotherapy. 
The benefit of cyclophosphamide, methotrexate and 5-fluorouracil (CMF) chemotherapy to patients with triple-negative, node-negative breast cancer is notable (32). One previous study indicated that there was no additional benefit associated with the cyclophosphamide, epirubicin and 5-fluorouracil (CEF) regimen over $\mathrm{CMF}$, suggesting that non-anthracycline regimens may be sufficient in intrinsic subtypes; however, additional studies are required (33).

Therefore, the lymph node status, not stage of disease, was regarded as an independent prognostic indicator for OS and DFS. For this reason, the present study considered that the patients with large numbers of lymph node metastasis may not be suitable for FEC adjuvant chemotherapy, but may receive taxane-containing chemotherapy regimens. A previous study reported that patients with node-positive breast cancer responded better to docetaxel compared with fluorouracil (34).

In total, 40 of the 239 TNBC patients $(16.7 \%)$ in the present study had a family history of breast cancer, which was not significantly increased compared with the non-TNBC subgroup total of $13 \%$ reported by Bhatti et al (35). Haffty et al concluded that TNBC exhibits an increased proportion of positive family history of breast cancer (36). Zhang et al reported that, in China, there was no statistically significant difference in the family history of TNBC and non-TNBC groups (37).

For tumor sizes of $<2 \mathrm{~cm}$, the rate of lymph node metastasis was $27.9 \%$ (24/86), compared with $48.4 \%$ for tumor sizes of $>2 \mathrm{~cm}$ (74/153). Therefore, tumor size was not indicated to be associated with lymph node metastasis, which is in agreement with several studies $(17,36,38)$. The present study, which assessed the association between tumor size and lymph node metastasis, produced varying results. Kandel et al demonstrated that $50 \%$ of patients with TNBC developed lymph node metastases when the average tumor size of TNBC was $2 \mathrm{~cm}$ (39). However, Haffty et al suggested that tumor size was not associated with lymph node metastasis (36).

Additionally, in the first year after diagnosis in the present study, the DFS rate for patients with TNBC was $95.0 \%$ (227/239), which was increased compared with that in the non-TNBC group of another study (18). This finding may be attributed to the indication that TNBC appears to be more sensitive to chemotherapy compared to non-TNBC (40). Therefore, patients with TNBC may achieve increased short-term DFS rates. In brief, TNBC patients have a poorer OS time and tend to relapse sooner compared with patients with other breast cancer subtypes (41). The present study reports that lymph node status is an effective prognostic parameter for TNBC patients, particularly for those that exhibit the N3 stage of disease; however, the effect of stages of disease is decreased. Therefore, a larger sample size is required in order to verify the results of the present study. In summary, the present study presents evidence that lymph node status may predict the prognosis of TNBC patients receiving FEC adjuvant chemotherapy in China. Patients with N0-2 may obtain the most benefit from FEC.

\section{Acknowledgements}

The present study was supported by Harbin Medical University Cancer Hospital (grant no., JJZ2011-02), Heilongjiang Provincial Department of Education Project (grant no.,
11541140) and Heilongjiang Provincial Bureau of Health (grant no., 2009-012).

\section{References}

1. Alkis N, Durnali AG, Arslan UY, Kocer M, Onder FO, Tokluoglu S, Celenkoglu G, Muallaoglu S, Utkan G, Ulas A, et al: Optimal timing of adjuvant treatment in patients with early breast cancer. Med Oncol 28: 1255-1259, 2011.

2. Perou CM, Sørlie T, Eisen MB, van de Rijn M, Jeffrey SS, Rees CA, Pollack JR, Ross DT, Johnsen H, Akslen LA, et al: Molecular portraits of human breast tumours. Nature 406: 747-752, 2000.

3. Ono M, Tsuda H, Shimizu C, Yamamoto S, Shibata T, Yamamoto H, Hirata T, Yonemori K, Ando M, Tamura K, et al: Tumor-infiltrating lymphocytes are correlated with response to neoadjuvant chemotherapy in triple-negative breast cancer. Breast Cancer Res Treat 132: 793-805, 2012.

4. Abd El-Rehim DM, Pinder SE, Paish CE, Bell J, Blamey RW, Robertson JF, Nicholson RI and Ellis IO: Expression of luminal and basal cytokeratins in human breast carcinoma. J Pathol 203: 661-671, 2004.

5. Carey LA, Perou CM, Livasy CA, Dressler LG, Cowan D, Conway K, Karaca G, Troester MA, Tse CK, Edmiston S, et al: Race, breast cancer subtypes, and survival in the Carolina Breast Cancer Study. JAMA 295: 2492-2502, 2006.

6. Nielsen TO, Hsu FD, Jensen K, Cheang M, Karaca G, Hu Z, Hernandez-Boussard T, Livasy C, Cowan D, Dressler L, et al: Immunohistochemical and clinical characterization of the basal-like subtype of invasive breast carcinoma. Clin Cancer Res 10: 5367-5374, 2004.

7. Prat A and Perou CM: Deconstructing the molecular portraits of breast cancer. Mol Oncol 5: 5-23, 2011.

8. Dawson SJ, Provenzano E and Caldas C: Triple negative breast cancers: Clinical and prognostic implications. Eur J Cancer 45 (Suppl 1): 27-40, 2009.

9. Bauer KR, Brown M, Cress RD, Parise CA and Caggiano V: Descriptive analysis of estrogen receptor (ER)-negative, progesterone receptor (PR)-negative, and HER2-negative invasive breast cancer, the so-called triple-negative phenotype: A population-based study from the California cancer Registry. Cancer 109: 1721-1728, 2007.

10. Irvin WJ Jr and Carey LA: What is triple-negative breast cancer? Eur J Cancer 44: 2799-2805, 2008.

11. Pal SK, Childs BH and Pegram M: Triple negative breast cancer: Unmet medical needs. Breast Cancer Res Treat 125: 627-636, 2011.

12. Foulkes WD, Smith IE and Reis-Filho JS: Triple-negative breast cancer. N Engl J Med 363: 1938-1948, 2010.

13. Metzger-Filho O, Tutt A, de Azambuja E, Saini KS, Viale G, Loi S, Bradbury I, Bliss JM, Azim HA Jr, Ellis P, et al: Dissecting the heterogeneity of triple-negative breast cancer. J Clin Oncol 30: 1879-1887, 2012.

14. Gucalp A and Traina TA: Triple-negative breast cancer: Adjuvant therapeutic options. Chemother Res Pract 2011: 696208, 2011.

15. De Laurentiis M, Cianniello D, Caputo R, Stanzione B, Arpino G, Cinieri S, Lorusso V and De Placido S: Treatment of triple negative breast cancer (TNBC): Current options and future perspectives. Cancer Treat Rev 36 (Suppl 3): S80-S86, 2010.

16. Silver DP, Richardson AL, Eklund AC, Wang ZC, Szallasi Z, Li Q, Juul N, Leong CO, Calogrias D, Buraimoh A, et al: Efficacy of neoadjuvant Cisplatin in triple-negative breast cancer. J Clin Oncol 28: 1145-1153, 2010.

17. Rakha EA, El-Sayed ME, Green AR, Lee AH, Robertson JF and Ellis IO: Prognostic markers in triple-negative breast cancer. Cancer 109: 25-32, 2007.

18. Dent R, Trudeau M, Pritchard KI, Hanna WM, Kahn HK, Sawka CA, Lickley LA, Rawlinson E, Sun P and Narod SA: Triple-negative breast cancer: Clinical features and patterns of recurrence. Clin Cancer Res 13: 4429-4434, 2007.

19. Calza S, Hall P, Auer G, Bjöhle J, Klaar S, Kronenwett U, Liu ET, Miller L, Ploner A, Smeds J, et al: Intrinsic molecular signature of breast cancer in a population-based cohort of 412 patients. Breast Cancer Res 8: R34, 2006.

20. Mersin H, Yildirim E, Berberoglu U and Gülben K: The prognostic importance of triple negative breast carcinoma. Breast 17: 341-346, 2008 
21. Rodríguez-Pinilla SM, Sarrió D, Honrado E, Hardisson D, Calero F, Benitez J and Palacios J: Prognostic significance of basal-like phenotype and fascin expression in node-negative invasive breast carcinomas. Clin Cancer Res 12: 1533-1539, 2006.

22. Rodríguez-Pinilla SM, Sarrió D, Honrado E, Moreno-Bueno G, Hardisson D, Calero F, Benítez J and Palacios J: Vimentin and laminin expression is associated with basal-like phenotype in both sporadic and BRCA1-associated breast carcinomas. J Clin Pathol 60: 1006-1012, 2007.

23. Reis-Filho JS, Milanezi F, Steele D, Savage K, Simpson PT, Nesland JM,PereiraEM,Lakhani SR and SchmittFC: Metaplastic breast carcinomas are basal-like tumours. Histopathology 49: $10-21,2006$

24. Abdulkarim BS, Cuartero J, Hanson J, Deschênes J, Lesniak D and Sabri S: Increased risk of locoregional recurrence for women with T1-2N0 triple-negative breast cancer treated with modified radical mastectomy without adjuvant radiation therapy compared with breast-conserving therapy. J Clin Oncol 29: 2852-2858, 2011.

25. Hernandez-Aya LF, Chavez-Macgregor M, Lei X, Meric-Bernstam F, Buchholz TA, Hsu L, Sahin AA, Do KA Valero V, Hortobagyi GN, et al: Nodal status and clinical outcomes in a large cohort of patients with triple-negative breast cancer. J Clin Oncol 29: 2628-2634, 2011.

26. Minn AJ, Gupta GP, Siegel PM, Bos PD, Shu W, Giri DD, Viale A, Olshen AB, Gerald WL and Massagué J: Genes that mediate breast cancer metastasis to lung. Nature 436: 518-524, 2005.

27. Bertucci F, Finetti P, Cervera N, Charafe-Jauffret E, Mamessier E, Adélaïde J, Debono S, Houvenaeghel G, Maraninchi D, Viens P, et al: Gene expression profiling shows medullary breast cancer is a subgroup of basal breast cancers. Cancer Res 66: 4636-4644, 2006.

28. Fadare O, Wang SA and Hileeto D: The expression of cytokeratin 5/6 in invasive lobular carcinoma of the breast: Evidence of a basal-like subset? Hum Pathol 39: 331-336, 2008.

29. Oakman C, Viale G and Di Leo A: Management of triple negative breast cancer. Breast 19: 312-321, 2010

30. Sihto H, Lundin J, Lundin M, Lehtimäki T, Ristimäki A, Holli K, Sailas L, Kataja V, Turpeenniemi-Hujanen T, Isola J, et al: Breast cancer biological subtypes and protein expression predict for the preferential distant metastasis sites: A nationwide cohort study. Breast Cancer Res 13: R87, 2011.

31. Kennecke H, Yerushalmi R, Woods R, Cheang MC, Voduc D, Speers $\mathrm{CH}$, Nielsen TO and Gelmon K: Metastatic behavior of breast cancer subtypes. J Clin Oncol 28: 3271-3277, 2010.
32. Colleoni M, Cole BF, Viale G, Regan MM,Price KN, Maiorano E, Mastropasqua MG, Crivellari D, Gelber RD, Goldhirsch A, et al: Classical cyclophosphamide, methotrexate, and fluorouracil chemotherapy is more effective in triple-negative, node-negative breast cancer: Results from two randomized trials of adjuvant chemoendocrine therapy for node-negative breast cancer. J Clin Oncol 28: 2966-2973, 2010

33. Cheang MC, Voduc KD, Tu D, Jiang S, Leung S, Chia SK Shepherd LE, Levine MN, Pritchard KI, Davies S, et al: Responsiveness of intrinsic subtypes to adjuvant anthracycline substitution in the NCIC.CTG MA.5 randomized trial. Clin Cancer Res 18: 2402-2412, 2012.

34. Hugh J, Hanson J, Cheang MC, Nielsen TO, Perou CM, Dumontet C, Reed J, Krajewska M, Treilleux I, Rupin M, et al: Breast cancer subtypes and response to docetaxel in node-positive breast cancer: Use of an immunohistochemical definition in the BCIRG 001 trial. J Clin Oncol 27: 1168-1176, 2009.

35. Bhatti AB, Khan AI, Siddiqui N, Muzaffar N, Syed AA, Shah MA and Jamshed A: Outcomes of triple-negative versus non-triple-negative breast cancers managed with breast-conserving therapy. Asian Pac J Cancer Prev 15: 2577-2581, 2014.

36. Haffty BG, Yang Q, Reiss M, Kearney T, Higgins SA, Weidhaas J, Harris L, Hait W and Toppmeyer D: Locoregional relapse and distant metastasis in conservatively managed triple negative early-stage breast cancer. J Clin Oncol 24: 5652-5657, 2006.

37. Zhang L, Hao C, Dong G and Tong Z: Analysis of Clinical Features and Outcome of 356 Triple-Negative Breast Cancer Patients in China. Breast Care (Basel) 7: 13-17, 2012.

38. Tischkowitz M, Brunet JS, Bégin LR, Huntsman DG, Cheang MC, Akslen LA, Nielsen TO and Foulkes WD: Use of immunohistochemical markers can refine prognosis in triple negative breast cancer. BMC Cancer 7: 134, 2007.

39. Kandel MJ, Stadler Z, Masciari S, Collins L, Schnitt S, Harris L, Miron A, Richardson A and Garber JE: Prevalence of BRCA1 mutations in triple negative breast cancer (BC). J Clin Oncol 24 (Suppl 18): 508, 2006.

40. Carey LA, Dees EC, Sawyer L, Gatti L, Moore DT, Collichio F, Ollila DW, Sartor CI, Graham ML and Perou CM: The triple negative paradox: Primary tumor chemosensitivity of breast cancer subtypes. Clin Cancer Res 13: 2329-2334, 2007.

41. Kaplan HG, Malmgren JA and Atwood M: T1N0 triple negative breast cancer: Risk of recurrence and adjuvant chemotherapy. Breast J 15: 454-460, 2009. 